$\mathbb{T}$ periodica polytechnica

Chemical Engineering

$56 / 2$ (2012) 49,54

doi: 10.3311/pp.ch.2012-2.01

web: http://www.pp.bme.hu/ch

(c) Periodica Polytechnica 2012

RESEARCH ARTICLE

\section{Application of photocatalytic procedure combined with ozonation for treatment of industrial wastewater - a case study}

\author{
Ottó Horváth / Erzsébet Szabó-Bárdos / Zoltán Zsilák / Gyula Bajnóczi
}

Received 2012-05-15, accepted 2012-10-04

\begin{abstract}
Several kinds of industrial wastewaters contain pollutants which cannot be entirely removed by physico-chemical treatments. In this case study wastewaters of a metal-working factory were purified. The results clearly indicated that $\mathrm{TiO}_{2}$-based heterogeneous photocatalysis combined with ozonation can efficiently decrease the COD value of the effluent from the cleaning plant currently applied, thus a final biological treatment ensures the required new (higher) level of purity. However, for wastewaters of large volume, which are generally mixtures of various process waters of different origins, the application of this heterogeneous photocatalysis at the end of the purification chain is not reasonable because of the high costs of investment. Insertion of the combined method into the middle of the cleaning technology, as a pre-treating stage of a heavily polluted constituent (an emulsion in this case) of the whole mixture before the biological treatment, is more cost effective. In the most economical procedure the combined method is applied for the emulsion diluted with weakly polluted wash waters. Thus, the subsequent biological treatment of the total mixture decreases the COD to $116 \mathrm{mg}$ $d m^{-3}$.
\end{abstract}

\section{Keywords}

heterogeneous photocatalysis $\cdot$ titanium dioxide $\cdot$ ozonation . wastewater treatment $\cdot$ mineralization

\section{Ottó Horváth}

Department of General and Inorganic Engineering, University of Pannonia, H-8200 Veszprém, Egyetem Street 10, Hungary

e-mail: otto@mk.uni-pannon.hu

\section{Erzsébet Szabó-Bárdos}

Department of General and Inorganic Engineering, University of Pannonia, H-8200 Veszprém, Egyetem Street 10, Hungary

\section{Zoltán Zsilák}

Department of General and Inorganic Engineering, University of Pannonia, H-8200 Veszprém, Egyetem Street 10, Hungary

\section{Gyula Bajnóczi}

Körte Környezettechnika Kft., 2330 Dunaharaszti, Móra F. u. 9., Hungary

\section{Introduction}

Surface waters are polluted with considerable amounts of toxic or dangerous materials (mostly of industrial origins, which cannot be approriately removed by conventional cleaning technologies). Hence, increasing demands have been arisen to develop new procedures, which are environmentally friendly, using little or no chemical additives, economical and efficient against a wide range of organic compounds. Possible techniques may be membrane technology, vacuum evaporation, biological treatment and UV oxidation photocatalysis [1,2]. The latter two methods decompose the organic pollutants, deviating from the first two procedures, which only concentrate the contaminants. However, their costs of investment, especially in the case of the photocatalytic procedure, are relatively high, thus their applicability ought to be thoroughly examined from economic point of view.

Photocatalytic detoxification of wastewaters belongs to the Advanced Oxidation Processes (AOP) [3]. In the past decade, the purification methods utilizing UV light-driven catalytic treatment were more frequently applied in the modern environmental protecting procedures. In these photocatalytic degradation processes the oxidizing agent is oxygen and/or ozone, or solution of hydrogen peroxide, which finally became the part of the simple inorganic end-products of the mineralization (such as $\mathrm{H}_{2} \mathrm{O}$ or $\mathrm{CO}_{2}$ ). The most widely used photocatalyst applied for wastewater treatment is nanosized titanium dioxide semiconductor [4,5]. Irradiation in the near UV range generates electron-hole pairs in the $\mathrm{TiO}_{2}$ nanoparticles. These opposite charges may recombine or, reaching the surface of the catalyst particle, can participate in redox reactions with $\mathrm{H}_{2} \mathrm{O}, \mathrm{HO}^{-}$or dissolved $\mathrm{O}_{2}$, producing highly reactive species such as $\mathrm{HO}^{\bullet}$ and $\mathrm{HO}_{2}^{\bullet}$, which efficiently oxidize the organic pollutants in the bulk solution. Contaminants adsorbed on the surface of the catalyst particles can also directly react with the photochemically produced holes and electrons, promoting the processes of mineralization.

Thorough studies on $\mathrm{TiO}_{2}$-based photocatalytic mineralization of a wide range of organic contaminants were carried out in the past decade [6-9]. Several methods developed have already 
been applied in practical purification procedures [9, 10$]$.

The combination of heterogeneous photocatalyis with ozonation can considerably increase the degradation efficiency, offering a very promising and powerful purification technique against a wide range of organic pollutants of both aliphatic [11,12] and aromatic [13] as well as surface active [14] character. This procedure can be successfully applied for oxidative decomposition of even the most dangerous contaminants such as polycyclic aromatic hydrocarbons (PAHs) [15, 16].

The main goal of the present study was to find the most appropriate place of this combined method in the whole purification procedure applied for wastewaters of a metal-working factory, in economic and technological respects.

\section{Experimental}

\subsection{Materials}

In all experiments in this study, the titanium dioxide catalyst used was Degussa P25 (70\% anatase, 30\% rutile; with a surface area of $\left.50 \mathrm{~m}^{2} \mathrm{~g}^{-1}\right)$. The concentration of $\mathrm{TiO}_{2}$ was $1 \mathrm{~g} \mathrm{dm}^{-3}$ in all cases. Compressed air was introduced into the reaction mixtures from gas bottles both for stirring and for serving (with its $\mathrm{O}_{2}$ content) as electron acceptor. Besides $\mathrm{O}_{2}$, in most of the experiments, also $\mathrm{O}_{3}$ produced by a LAB2B ozone generator in the same air stream functions as an oxidizer. High purity water used in this study was double distilled and then purified with a Milli-Q system.

\subsection{Photochemical experiments}

Photochemical experiments were performed using a laboratory-scale reactor with an effective volume of $2.5 \mathrm{dm}^{3}$. The heterogeneous reaction mixture $\left(\mathrm{TiO}_{2}\right.$ suspension) was circulated by a peristaltic pump through the reactor and the buffer vessel and by continuously bubbling air with a flow rate of $40 \mathrm{dm}^{3} \mathrm{~h}^{-1}$. The photon flux of the internal light source (40W, $\lambda_{\max }=350 \mathrm{~nm}$, i.e., UVA range) was determined by potassium tris(oxalato)-ferrate(III) chemical actinometry [17, 18]. It was estimated to be $4.3 \times 10^{-6} \mathrm{~mol}$ photon $\mathrm{dm}^{-3} \mathrm{~s}^{-1}$.

\subsection{Biological treatment}

In the biological stage of the wastewater treatment in this study, a technology based on a sequencing batch reactor (SBR) was applied. SBR is a fill-draw activated sludge treatment system, in which the processes are identical to those in the conventional continuous flow activated sludge system. However, deviating from the latter procedures, SBR is a compact and timeoriented system, in which all the processes are carried out sequentially in the same tank. An operating cycle of an SBR reactor comprises five distinctive (fill, react, settle, draw and idle) phases [19]. The operational flexibility of this system allows designers to use the SBR to meet many different treatment objectives.

\subsection{Analytical procedures}

For analysis, $4 \mathrm{~cm}^{3}$ samples were taken with a syringe from the reactor. The solid phase of samples, when necessary, was separated by filtration using Millipore Millex-LCR PTFE 0.45 $\mu \mathrm{m}$ filters. The $\mathrm{pH}$ of the aqueous phase of the reaction mixture was measured with a SEN Tix 41 electrode.

Mineralization was followed by measuring the total organic carbon (TOC) concentration, with a Thermo Electron Corporation TOC TN 1200 apparatus. The dichromate method was applied for the determination of the chemical oxygen demand (COD). The degradation of the main pollutants in the preliminary experiments was followed by gas chromatography, using a Shimadzu GC-2010 equipment. For a qualitative monitoring, absorption spectra of the reaction mixtures were also recorded with a PerkinElmer Lambda 25 spectrophotometer.

The ozone concetration was determined by iodometry, using sodium iodide as reagent and sodium thiosulfate for the titration of the iodine formed. The ozone dosage was estimated to be $3.5 \times 10^{-4} \mathrm{~mol} \mathrm{dm}^{-3} \mathrm{~min}^{-1}$.

\section{Results and Discussion}

3.1 Photocatalysis of the annual average wastewater sample after physico-chemical treatments

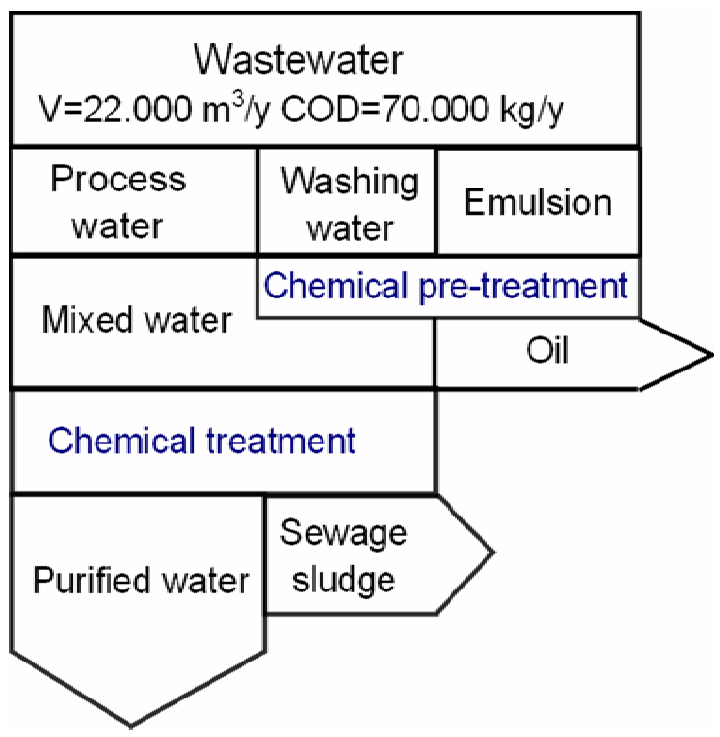

Scheme 1. Basic technology for the treatment of an industrial wastewater mixture.

The industrial wastewater dealt with in this work resulted from a factory specialized in metal-work and galvanization. It was a mixture of several polluted waters of various origins, such as process water, washing water, and emulsion as well. The typical components of this mixture were various lubricants (oil, grease), ethoxylates of unsaturated fatty alcohols, fatty acid amids as well as benzyl and methyl ethers of fatty alcohols. The different polluted waters inflowing into the cleaning plant underwent individual pre-treatments and also a common purification procedure (Scheme 1). However, at the end of this procedure the value of the chemical oxygen demand (COD) of the effluent was one order of magnitude higher than the officially allowed value 


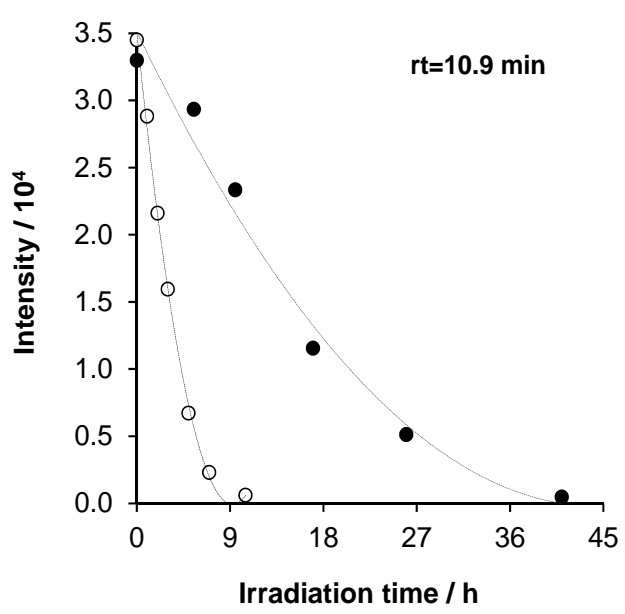

Fig. 1. The decay of the predominant pollutant in mixture (at 10.9 min retention time) followed by GC during the treatment with photocatalysis (•) and combined method (o).

(150 $\mathrm{mg} \mathrm{dm}^{3-}$ ). Hence a post-treatment seemed to be a possible solution. For this purpose, application of both photochemical and biological methods were reasonable because both result in the mineralization of the pollutants, deviating from other techniques which just separate them. Thus we tested the effect of the photocatalytic treatment before and after the biological stage.

The aim of our first series of experiments was the comparison between the effiency of the heterogeneous photocatalysis and that of its combination with ozonation. The progress of the degradation was followed by both GC-monitoring of the decay of the predominant pollutant (ethoxylate of a fatty alcohol) (Fig. 1) and measuring the total organic carbon content (TOC) in the mixture treated (Fig. 2).

As Fig. 1 indicates, the conversion of the main pollutant (with retention time of $10.9 \mathrm{~min}$ ) is about 4.8 times faster with the combined procedure than in the case of the photocatalysis alone. The difference between the inital rates of mineralization (i.e., TOC decrease) is somewhat smaller because during the conversion of pollutants, especially in the first period of the treatments, intermediates are formed, the TOC contribution of which is very significant. Hence, the ratio of the initial mineralization rates is about 2.8 as the data of Table 1 show.

These results unambiguously prove that the combined method is significantly more efficient than the heterogeneous photocatalysis alone. Moreover, independent studies indicated that in this combination a synergistic effect enhances the resulting efficiency compared to the sum of the efficiencies of the individual methods.

Tab. 1. Initial rates of degradation (main pollutant) and mineralization (TOC) at treatments with photocatalysis and its combination with ozonation.

\begin{tabular}{lll}
\hline \multirow{2}{*}{ Type of experiment } & Initial rate \\
\cline { 2 - 3 } & $\begin{array}{l}\text { Main pollutant } \\
\text { (GC intensity) }\end{array}$ & $\begin{array}{l}\text { TOC } \\
(\mathbf{m g ~ d m}\end{array}$ \\
\hline Air $+\mathrm{TiO}_{2}+$ UV & 1590 & 0.11 \\
\hline $\mathrm{O}_{3}+\mathrm{TiO}_{2}+\mathrm{UV}$ & 7630 & 0.31 \\
\hline
\end{tabular}

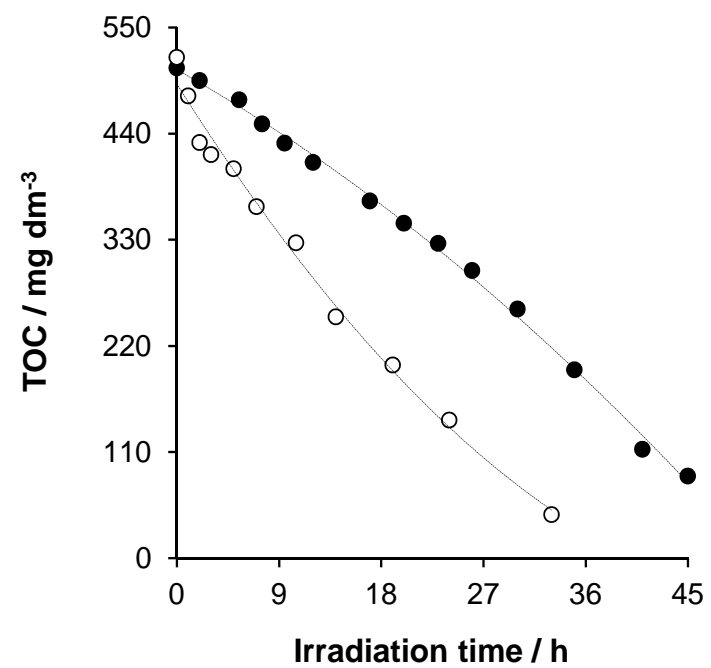

Fig. 2. The decrease of TOC during the treatment with photocatalysis $(\bullet)$ and combined method (o).

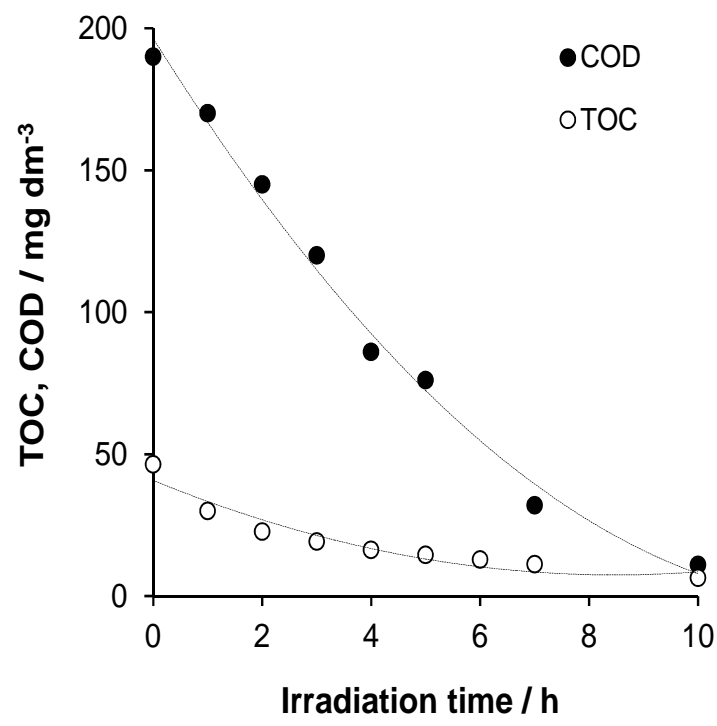

Fig. 3. The decrease of COD and TOC during the treatment of the effluent with the combined procedure after the biological stage.

Hence, in the further experiments exclusively the combination of heterogeneous photocatalysis and ozonation was applied. The 24-hour treatment with the combined method decreased the COD value of the effluent sample from 1470 to $229 \mathrm{mg} \mathrm{dm}^{-3}$. The wastewater treated in this way was of suitably high purity approaching the quality required for the output. The subsequent biological stage easily diminished its COD value below $150 \mathrm{mg}$ $\mathrm{dm}^{-5}$. However, for a practical application, due to the large volume of wastewater load of the UV oxidation stage (21718 $\mathrm{m}^{3}$ /year, ca. $60 \mathrm{~m}^{3} /$ day), the costs of investment would be extremely high.

Application of the photochemical and biological steps in a reversed order provided similar results. After a 2-week biological treatment the COD value decreased to about $200 \mathrm{mg} \mathrm{dm}^{-3}$. A subsequent (final) combined photochemical procedure resulted in an extremely low COD value $\left(11 \mathrm{mg} \mathrm{dm}^{-3}\right.$, Fig. 3), almost the quality of drinking water, much better than the required limit for 
the output. However, similarly to the previous case, the costs of investment would be enormous because of the large volume of wastewater input into this stage $\left(43118 \mathrm{~m}^{3} / \mathrm{year}\right.$, ca. 120 $\mathrm{m}^{3} /$ day).

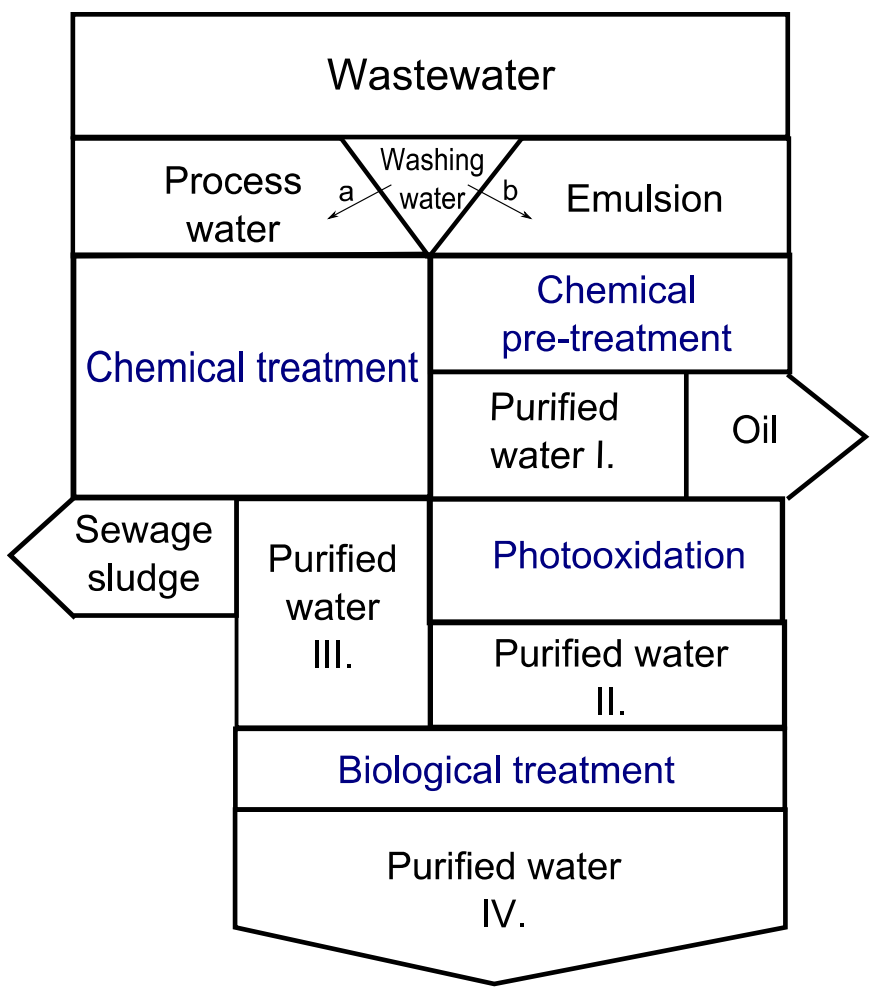

Scheme 2. Purification technology with the combined (photooxidation) stage applied for the highly polluted emulsion before the biological treatment of the entire (merged) effluent; a) fivefold dilution with outer water source, b) dilution with weakly contaminated washing water.

\subsection{Photocatalysis and ozonation of the emulsion part of} the wastewater mixture

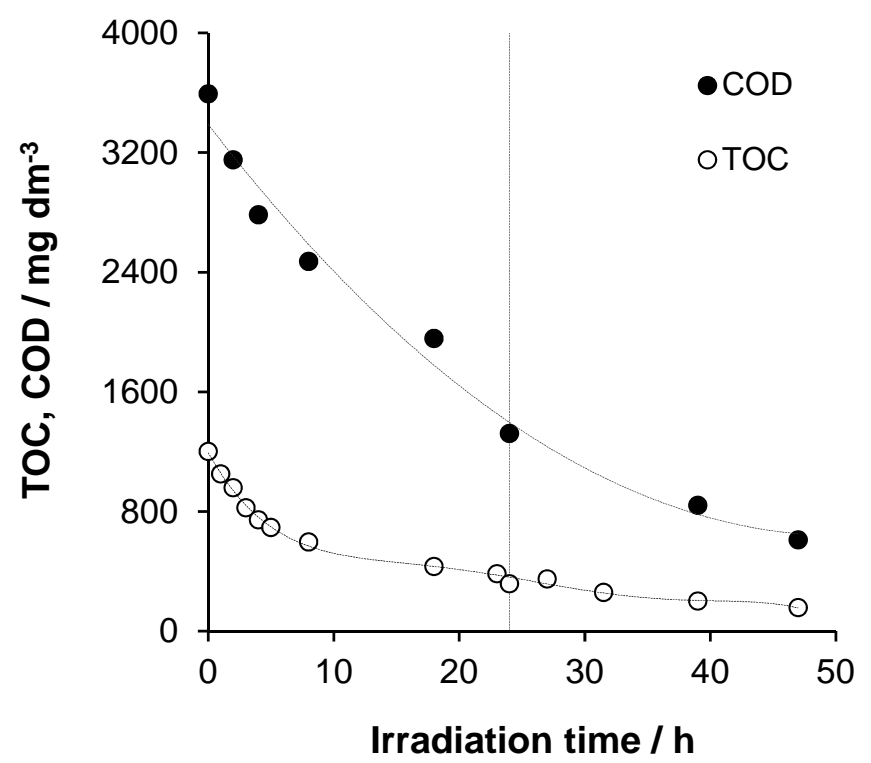

Fig. 4. The decrease of COD and TOC during the combined procedure applied for the aqueous part of the pre-treated emulsion after a fivefold dilution. (The vertical dashed line designates the 24-hour period.)
For diminishing the costs of investment and operation of the photochemical stage, this relatively expensive method is more reasonable to be applied for a much smaller but extremely heavily polluted part of the wastewater mixture. This very contaminated contribution is an emulsion, the COD value of the aqueous part of which was as high as $13592 \mathrm{mg} \mathrm{dm}^{-3}$ even after the physico-chemical pre-treatment (decomposition) (Scheme 2).

Since this COD value was much too high for an efficient photochemical treatment, a fivefold dilution of the sample had to be made before the combined stage. As Fig. 4 indicates, a 24-hour treatment with the combined method diminished the COD value of the diluted sample from 3300 to $1320 \mathrm{mg} \mathrm{dm}^{-3}$. This more than $60 \%$ COD decrease was accompanied by a considerable increase of the acidity of the sample treated.

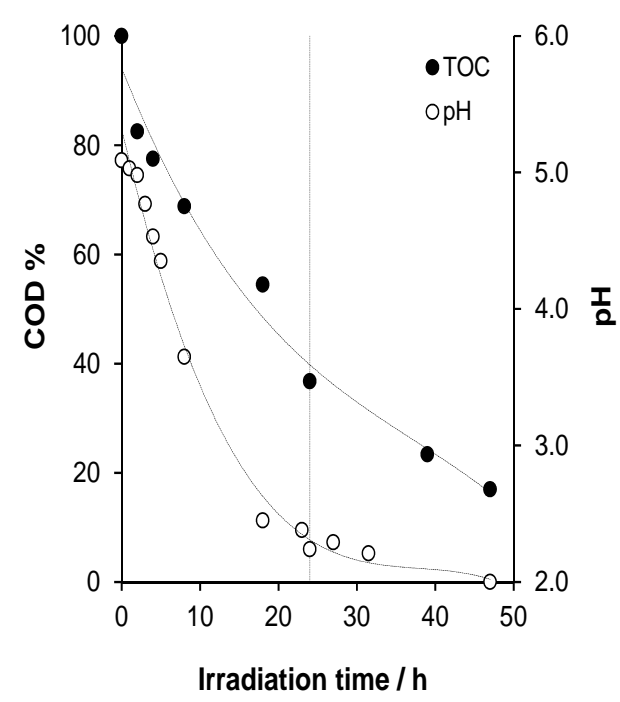

Fig. 5. The decrease of COD (in \%) and $\mathrm{pH}$ during the combined procedure applied for the aqueous part of the pre-treated emulsion after a fivefold dilution. (The vertical dashed line designates the 24-hour period.)

The initial value of $\mathrm{pH}$ (ca. 5) decreased to about 2.3 within the irradiation period, and to 2.0 after a 48-hour irradiation as shown in Fig. 5. Such an increase of the hydrogen ion concentration during the photooxidation of this kind of wastewater is a general phenomenon due to the formation of simple organic and inorganic acids. Also in this respect is advantageous to apply this method only for a part of the wastewater mixture in the middle of the whole purification technology. Thus, after the photochemical treatment, mixing this part with the other constituents of the total effluent undergoing the biological stage considerably increases the final $\mathrm{pH}$ towards the neutrality.

The final biological purification of the pre-treated mixture diminished its COD to $127 \mathrm{mg} \mathrm{dm}^{-3}$ (much below the prescribed limit of $150 \mathrm{mg} \mathrm{dm}^{-3}$ ). Since the volume of the input into the combined stage in this technological arrangement is considerably low (520 $\mathrm{m}^{3} /$ year, i.e., $1,4 \mathrm{~m}^{3} /$ day $)$, this procedure may be realized at relatively low costs of investment and operation. 


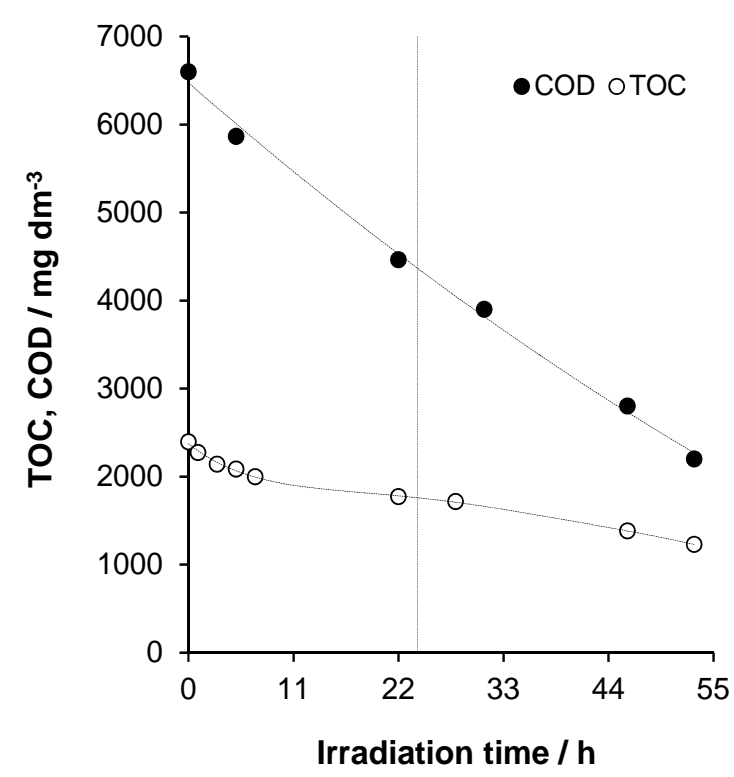

Fig. 6. The decrease of COD and TOC during the combined procedure applied for the pre-treated emulsion diluted with weakly polluted washing water. (The vertical dashed line designates the 24-hour period.)

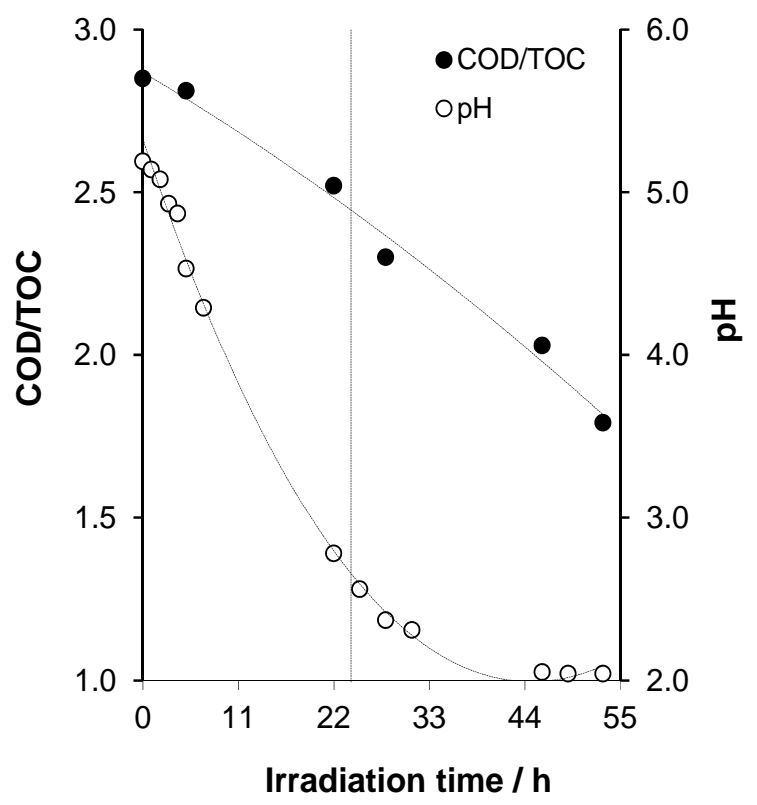

Fig. 7. The change of the $\mathrm{COD} / \mathrm{TOC}$ ratio and $\mathrm{pH}$ during the combined procedure applied for the pre-treated emulsion diluted with weakly polluted washing water. (The vertical dashed line designates the 24-hour period.)

3.3 Photocatalysis and ozonation of the emulsion mixed with weakly polluted washing water

Although the results of the previous compilation of purification steps seemed to be favourable, the dilution of the heavily polluted aqueous part of the pre-treated emulsion with an outer source of clean water is not reasonable or maybe even prohibited. Thus, improving the technology in this respect, in a much more reasonable solution a weakly contaminated input constituent of the wastewater was applied for the dilution of the emulsion. The collection of various wash waters (designated as „washing water") was utilized for this purpose as indicated in Scheme 2 (arrow with „b”). Although the COD value of the pre-treated emulsion was still rather high in this case $(6600 \mathrm{mg}$ $\mathrm{dm}^{-3}$ ), it was diminished to $4460 \mathrm{mg} \mathrm{dm}^{-3}$ by a 24 -hour combined procedure, while $2200 \mathrm{mg} \mathrm{dm}^{3-}$ was reached after a 48 hour treatment (Fig. 6).

Also in this case a significant decrease of $\mathrm{pH}$ was observed during the irradiation (Fig. 7) because oxidation resulted in the formation of various acids. In accordance with this explanation, COD decreased considerably faster than TOC did, indicating that oxygenation of the pollutants led to the formation of acidic intermediates. In such processes the oxidation state of all the oxygenated carbon atoms increases, while their number just moderately changes. Only the terminal carbon atoms can be mineralized, forming carbonate or its protonated derivatives, which results in TOC decrease.

The final biological purification of the pre-treated mixture, following the 24-hour combined stage, reached a COD value of $116 \mathrm{mg} \mathrm{dm}^{-3}$, reliably satisfying the official requirement. Hence, this technological arrangement unambiguously proved to be the most reasonable one to put into practice as a consequence of the fairly low load at the photochemical stage ( 840 $\mathrm{m}^{3} /$ year, $2,3 \mathrm{~m}^{3} /$ day).

\section{Conclusions}

Although the heterogeneous photocatalysis is an effective procedure for wastewater treatment, its application at the end of the purification technology is not reasonable because of the high costs of investment and operation - also in the case of combination with ozonation. Application of the combined method is more cost effective as a pre-treating stage for the purification of a heavily polluted part of the wastewater mixture, an emulsion in this case, before the biological treatment. In the most economical arrangement of the individual purification steps, the combined method was applied for the emulsion diluted with moderately polluted washing water, before the final biological purification.

\section{Acknowledgement}

This work was presented at the Conference of Chemical Engineering, Veszprém, 2012.

This work has been carried out in the frame of the projects TÁMOP-4.2.1/B-09/1/KONV-2010-0003 and TÁMOP-4.2.2/B10/1-2010-0025. The projects have been realized with the support of the Hungarian Government and the European Union, with the co-funding of the European Social Fund.

\section{References}

1 Szabó-Bárdos E, Zsilák Z, Lendvay G, Horváth O, Markovics O, Hoffer A., Törö N, Photocatalytic degradation of 1,5-naphthalenedisulfonate on colloidal titanium dioxide, J. Phys. Chem. 112 (2008), 14500-14508, DOI 10.1021/jp803656f.

2 Szabó-Bárdos E a., Water Res. 45 (2011), 1617-1628, DOI 10.1016/j.watres.2010.11.045. 
3 Klavariotia M, Mantzavinosa M, Kassinos D, Removal of residual pharmaceuticals from aqueous systems by advanced oxidation processes, Environ. Int. 35 (2009), 402-417, DOI 10.1016/j.envint.2008.07.009.

4 Fujishima A, Rao T N, Tryk D A, Titanium dioxide photocatalysis, J. Photoch. Photobiol. C 1 (2000), 1-21, DOI 10.1016/S1389-5567(00)00002-2.

5 Gaya U I, Abdullah A H, Heterogeneous photocatalytic degradation of organic contaminants over titanium dioxide: A review of fundamentals, progress and problems, J. Photoch. Photobiol. C 9 (2008), 1-12, DOI 10.1016/j.jphotochemrev.2007.12.003.

6 Szabó-Bárdos E, Czili H, Horváth A, Photocatalytic oxidation of oxalic acid enhanced by silver deposition on a $\mathrm{TiO}_{2}$ surface, J. Photoch. Photobiol. A 154 (2002), 195-201, DOI 10.1016/S1010-6030(02)00330-1.

7 Szabó-Bárdos E, Czili H, Megyery-Balog K, Horváth A, Photocatalytic oxidation of oxalic acid enhanced by silver and copper deposition on $\mathrm{TiO}_{2}$ surface, Prog. Coll. Polym. Sci. 125 (2004), 42-48, DOI 10.1007/b13879.

8 Li Y, Zou L, Hu E, Photocatalytic degradation of dye effluent by titanium dioxide pillar pellets in aqueous solution, J. Environ. Sci. 16 (2004), 375379.

9 Szabó-Bárdos E, Zsilák Z, Horváth O, Photocatalytic degradation of anionic surfactant in titanium dioxide suspension, Prog. Coll. Pol. Sci. 135 (2008), 21-28, DOI 10.1007/2882_2008_096.

10 Thiruvenkatachari R, Vigneswaran S, Moon I S, A review on UV/TiO photocatalytic oxidation process, Korean J. Chem. Eng. 25 (2008), 64-72, DOI 10.1007/s11814-008-0011-8.

11 Ilisz I, Bokros A, Dombi A, $\mathrm{TiO}_{2}$ based heterogeneous photocatalytic water treatment combined with ozonation, Ozone Sci. Eng. 26 (2004), 585-594, DOI 10.1080/01919510490885406.

12 Addamo M, Augugliaro V, Lopez E G, Loddo V, Marci G, Palmisano $\mathbf{L}$, Oxidation of oxalate ion in aqueous suspensions of $\mathrm{TiO}_{2}$ by photocatalysis and ozonation, Catal. Today, posted on 2005, 612-618, DOI 10.1016/j.cattod.2005.07.030, (to appear in print).

13 Tong S, Xie D, Wei H, Liu W, Although some studies concerning the effect of $p H$ and ozone, Ozone Sci. Eng. 27 (2005), 233-238, DOI 10.1080/01919510590945804.

14 Oyama T, Yanagisawa I, Takeuchi M, Koike T, Serpone N, Hidaka H, Remediation of simulated aquatic sites contaminated with recalcitrant substrates by $\mathrm{TiO}_{2}$ ozonation under natural sunlight, Appl. Catal. B: Environ 91 (2009), 242-246, DOI 10.1016/j.apcatb.2009.05.031.

15 Zhang L, Li P, Gong Z, Li X, Photocatalytic degradation of polycyclic aromatic hydrocarbons on soil surfaces using $\mathrm{TiO}_{2}$ under UV light, J. Hazard. Mater. 158 (2008), 478-484, DOI 10.1016/j.jhazmat.2008.01.119.

16 Woo O T, Chung W K, Wong K H, Chow A T, Wong P K., Photocatalytic oxidation of polycyclic aromatic hydrocarbons: intermediates identification and toxicity testing, J. Hazard Mater. 168 (2009), 1192-1199, DOI 10.1016/j.jhazmat.2009.02.170.

17 Rabek J F, Experimental methods in photochemistry and photophysics, Wiley-Interscience publication, John Wiley \& Sons Ltd., New York, 1982, pp. 944-946.

18 Kirk A D, Namasivayam C, Errors in ferrioxalate actinometry, Analytical Chemistry 55 (1983), 2428-2429, DOI 10.1021/ac00264a053.

19 Vigneswaran S, Sundaradivel M, Chaudhary D S, Sequencing Batch Reactors: Principles, Design/Operation and Case Studies, Water and Wastewater Treatment Technologies (Vigneswaran S, ed.), Vol. 2, EOLSS e-Book Library, 2009, pp. 24-43. 